\title{
INTERCELLULAR ADHESION MOLECULE-1 (ICAM-1) IN GINGIVAL CREVICULAR FLUID IN PERIODONTAL HEALTH AND PERIODONTITIS
}

\author{
Hasanuddin Thahir, * Wardihan Sinrang, ** \\ *Department of Periodontology Faculty of Dentistry Hasanuddin University \\ **Department of Physiology Faculty of Medicine Hasanuddin University
}

\begin{abstract}
The purpose of this study was to determine the difference between intercellular adhesion molecule-1 (ICAM-1) cytokine content in gingival crevicular fluid (GCF) on healthy periodontal and chronic periodontitis. It was also determine the treatment effects of hydrogen peroxide as subgingival irrigation in chronic periodontitis. Twenty participants were examined in this study. Gingival fluid collection method was carry out with strip paper technique and analyzed with enzyme-linked immunosorbent assay (ELISA). The result of the study showed that there was a significant difference of ICAM-1 on healthy site and periodontitis site, and there was a significant change of ICAM-1 content after treatment $(\mathrm{p}<0.05)$. We concluded that ICAM-1 in GCF is a sensitive indicator to differentiate healthy sites from those with periodontitis. Indonesian Journal of Dentistry 2006; Edisi Khusus KPPIKG XIV:397-399.
\end{abstract}

Key words: cell adhesion molecules; gingivai crevicular fluid; gingivitis; periodontitis.

\section{Introduction}

Periodontitis is a chronic inflammatory disease leading to the destruction of tooth-supporting structures. It is initiated and perpetuated by a group of predominantly Gram-negative and anaerobic bacteria that colonize the subgingival environment. The periodontopathogens may directly injure periodontal tissues and indirectly activate cellular and humoral immune systems which cause secondarily damage the periodontium. The incidence and rate of progression of periodontitis depend on complex interactions between periodonthopathic bacteria and host immuno-inflamatory responses.'

In the past few years, the central focus of research on periodontal diagnosis bas been on methods that attempt to identify high-risk subjects or high-risk sites within subjects before extensive damage to tissues has occurred. Traditional methods of diagnosis such as clinical attachment loss and probing depth are deficient with respect to accuracy and their ability to predict disease activity. These clinical measurements are retrospective, they only measure disease that has already occurred and are of limited value as diagnosis needs to be prospective. ${ }^{2}$ Therefore, and considerable attention has been directed towards the measurement of site-specific by products of the disease process in the gingival tissues or in the adjacent crevicular fluid. These site directed measurements may allow for a more definitive identification of susceptible individuals and may also allow for the evaluation of responsiveness to therapy.

A number of cell adhesion molecules have been detected as soluble circulating forms in human serum and other body fluid. This intercellular adhesion molecule-1 (ICAM-1) may influence cell 
interaction within gingival tissue and may also influence the interaction between bacteria and cell in the gingival crevice. Although some data exists on the distribution of ICAM in gingival tissue, very little is known about the expressions of these molecules in different forms of periodontal disease, during different stages of the disease, and in the healing process after therapy. The ICAM-1 have been found to be important in other inflammatory disease such as rheumatoid arthritis, but little information exists about their role in periodontal disease. $^{3,4}$

\section{Material and Methods}

Patients with chronic periodontitis were selected from Clinic of Department of Periodontology Hasanuddin University, Makassar. There were 20 patients ( $60 \%$ female; mean age $45 \pm 11.5$ [SD]), and 20 patients ( $58 \%$ female; mean age $42 \pm 4.5$ (SD) in the control group. Patients with periodontitis were scaled, and then irrigation was conducted with $1.5 \%$ hydrogen peroxide $4 \mathrm{ml}$ for two weeks. Gingival fluid collecting was carried out on $1^{\text {st }}$ day, $7^{\text {th }}$ day, and $21^{\text {st }}$ day after treatment. The inclusions criteria were: 1) Presentation of untreated advanced chronic periodontitis, with probing depth (PD) $\geq 5.0 \mathrm{~mm}$, clinical attachment loss (CAL) $\geq 3.0$ $\mathrm{mm}$, for periodontitis group; 2) Healthy systemic condition; 3) No prior periodontal treatments; 4) No use of any immunosuppressive treatments; and 5) No antibiotics or anti-inflammatory drugs taken within the preceding 6 months for control group. All the subjects who agreed to participate in the study signed an informed consent form and were examined at a screening session to verify their suitability for the study.

Gingival fluid collection was carried out with "filter paper strip method". The quadrant site where gingival fluid would be taken was isolated with cotton rolls and saliva, was dried by saliva ejector to reduce the contamination risk. The tooth side where the gingival fluid was taken was washed with a water stream and air dried with a spray for 5 seconds to ensure removal of tooth associated saliva. A strip of paper was carefully inserted into the crevice until a mild resistance was felt. The strip was removed after 30 seconds. Then the paper was placed into 500 ul sterile phosphate buffered saline and stored at $80^{\circ} \mathrm{C}$ until required. Samples were discarded if the paper strips were contaminated with blood or saliva, which was verified by visual inspection. A quantitative sandwich enzyme immunoassay technique was used to measure the level of soluble ICAM-1. Data taken from the result of GCF measurement was analyzed by computerization using SPSS program for windows version 11.5. All statistical tests were carried out using significance level of $5 \%$.

\section{Result.}

The result of the study showed that there was significant difference between treatment group on the day 1 and day $21(\mathrm{p}<0.05)$ while on the day 1 and day 7 there was no significant difference ( $>0.05$ ) (Table 1). In the control group there was no significant difference between day 1,7 , and day 21 after treatment $(\mathrm{p}>0.05)$ (Table 2)

Table 1. Intercellular adhesion molecule-l difference before and after subgingival irrigation with hydrogen peroxide $1.5 \%$.

\begin{tabular}{lcccc}
\hline $\begin{array}{l}\text { Perubahan } \\
\text { Hari }\end{array}$ & Mean & $\mathrm{N}$ & SD & Sig. \\
\hline CAMAWL & 1.86 & 20 & 0.124 & 0.090 \\
ICAM7 & 1.86 & 20 & 0.183 & \\
CAMAWI & 1.86 & 20 & 0.047 & 0.000
\end{tabular}

Table 2. Intercellular adhesion molecule-l difference of control group before and after $1^{\text {st }}, 7^{\text {th }}$ and $21^{\text {st }}$ day.

\begin{tabular}{lcccc}
\hline Perubahan Hari & Mean & $\mathrm{N}$ & $\mathrm{SD}$ & Sig. \\
\hline CAMAWL & 1.060 & 20 & 0.12 & 0.22 \\
ICAM7 & 0.080 & 20 & 0.18 & \\
CAMAWL & 1.060 & 20 & 0.12 & 0.080 \\
CAM21 & 1.10 & 20 & 0.15 & \\
\hline
\end{tabular}

\section{Discussion}

Nowadays, the focus of study on periodontal diagnosis is trying to use disease identification by cytokine screening that could be detected in gingival crevicular fluid. This method can identify high risk subject or risk side before more severe destruction on tissue occurred. Some cytokine related to periodontal disease are ICAM-1, IL-1, IL4, IL-6, IL8, IF-Y, TNF, Matrixmetalloproteinase (MMP), and 
growth factor (GF). This cytokine can be identified and found in gingival fluid. ${ }^{5}$ The cytokine ICAM-1 was first detected in normal human serum using immunobloting and ELISA. Subsequently, levels of ICAM-1 were shown to elevated in inflammation, infection and cancer, indicating that ICAM-1 may be a useful parameter for diagnosis and evaluating these pathological conditions. Previous studies investigating the involvement of inflammatory mediators have shown elevated levels in sites with periodontitis. It has been suggested that soluble forms of CAMs may be released as a consequence of cell damage possibly arising from cytokine induction. Thus, the higher level of ICAM-1 found in periodontitis sites may reflect the increased cellular damage evident at these sites. The total amounts of ICAM-1 found in this study decreased as the site category changed from periodontitis to healthy periodontal. ${ }^{6,7}$

In this study, the examination was ICAM-1 measurement that could be taken from gingival fluid before and after scaling and hydrogen peroxide $1.5 \%$ irrigation. This method had been used by Hannibal et al. $(2004)^{2}$ who examined the surface of periodontal tissue to differ the sick and healthy side. ${ }^{7}$ His study result showed that there was a significant difference of ICAM-1 content between the sick and healthy side. Therefore, this cytokine can be used as a sensitive indicator in diagnosis, evaluation and condition of pathologic periodontal tissue..$^{2,9}$

The result of study found the effect of treatment on $21^{\text {st }}$ day could reduce ICAM-1 content significantly $(p<0.05)$ and there was a significant difference between hydrogen peroxide group and control group. On $21^{\text {st }}$ day the result showed that the control group has no significant difference with treatment group $(p<0.05)$. This result revealed that the effect of $1.5 \%$ hydrogen peroxide application on day 21 had the same ICAM-1 value with control group. This finding indicated that ICAM-1 level in healthy side was lower than side with disease.

In this study, it has been found that $1.5 \%$ hydrogen peroxide subgingivally applicated after scaling could reduce the level of ICAM-1 from 1.86 $\mathrm{ng} / \mathrm{ml}$ to $1.12 \mathrm{ng} / \mathrm{ml}$ on $21^{\text {st }}$ day. The ICAM-1 level has been considered as healthy periodontal tissue as confirmed with Hannigan result $(2004)^{2}$, that showed the relationship between ICAM-1 level on periodontal fluid of periodontitis and healthy periodontal. His study showed that ICAM-1 level on healthy periodontal generated from gingival fluid is average $0.8 \mathrm{ng} / \mathrm{ml}$ while on periodontitis is average $1.8 \mathrm{ng} / \mathrm{ml}$.
It has been known that ICAM-1 is an indicator of inflammation process. The decrease of marker/indicator level is the decrease of inflammation process. Therefore, in this study, the decrease of ICAM-1 level could be concluded as decreased of inflammation process. That is why hydrogen peroxide can function as a factor that decreases the inflammation. In addition, the findings in this study could recommend ICAM-l measurement on gingival fluid to diagnose and determine the prognosis of periodontal disease.

Conventional periodontal treatment such as scaling and rootplaning followed by adjunctive treatment like disinfectant agent was aimed to remove periodontopathogen factor. But we must keep in mind that the destructive periodontal tissue on periodontitis case is an interaction between periodontopathogen bacteria and host responds. ${ }^{2,9}$ Therefore, the strategy of the treatment that must be developed is not only bacterial elimination as a causing factor but also the responds of host toward the treatment.

\section{References}

1. Kinane DF, Lindthe J. Pathogenesis of Periodontitis, in: Linde J, Karring T, Lang NP (eds,) Clinical Periodontology and Implant Dentistry. Copenhagen: Munksgaard 1997: 189-225

2. Hannigan E, Connel] DPO, Hannigan A, Bucley LA. Soluble Adhesion Molecules in Gingival Crevicular Fluid in Periodontal Health and Disease. J Periodontol 2004; 75:54650 .

3. Crawford $\mathrm{JM}$, Watanabe $\mathrm{K}$. Cell Adhesion Molecules in Inflammation and Immunity. Crit Rev Oral Biol Med 1994;5:91+123

4. Littler AJ, Buckley CD, Wordsworth P, Collins I, Martinson J, Simmons DL. A Distinct Profile of Six Soluble Adhesion Molecules (ICAM-1, VCAM-1, E-Selectin, L-Selectin And P. Selectin) in Rheumatoid Arthritis. Br $J$ Rheumatol 1997; 36:164-69.

5. Romagnani S. The Thl/Th2 Paradigm. Immunol Today 1997; 18:263-66.

6. Masada MP, Persson M, Kenney JJ, Lee SW, Page RC, Allison AC. Measurement of $\mathrm{IL}-\mathrm{l} \alpha$ and $\mathrm{IL}-1 \quad \beta$ in GCF implications for the Pathogenesis of Periodontal Disease. $J$ Periadont Res 1990;25:156-63.

7. Lamster IB, Harper DS, Fiorello LA, Gemmel E, Walsh LJ, Savage NW, Seymour GJ. Adhesion Molecule Expression in Chronic Inflammatory Periodontal Disease Tissue. $J$ Periodont Res 1994;29:46-53.

8. Smith QT, Hinrichs JE, Melnyk RS, Gingival Crevicular Fluid Myelloperoxidase at Periodontitis Sites. $J$ Periodontol 1986;21:45-5S

9. Stashenko P, Jandinski JJ, Fujiyoshi P, Rynar J, Socransky SS. Tissue Levels of Bone Resorptive Cytokines in Periodontal Disease. $J$ Periodont 1991;62;504-9. 